\title{
Dimensionamento e avaliação da viabilidade técnica e econômica de uma coluna de absorção para purificação de biogás
}

\begin{abstract}
Claudia Luiza Manfredi Gasparovic

Gasparovic

Claudiag@alunos.utfpr.edu.br

Paraná - (UTFPR), Medianeira, Paraná,

Brasil

\section{Eduardo Eyng}

eduardoeyng@utfpr.edu.br

Universidade Tecnológica Federal do Paraná - (UTFPR), Medianeira, Paraná, Brasil

Laercio Mantovani Frare

laercio@ utfpr.edu.b

Universidade Tecnológica Federal do Paraná - (UTFPR), Medianeira, Paraná, Brasil

Larissa de Bortolli Chiamolera Sabbi

larissasabbi@utfpr.edu.br

Universidade Tecnológica Federal do

Paraná - (UTFPR), Medianeira, Paraná,

Parana
Brasil
\end{abstract}

\author{
RESUMO
}

Nas últimas décadas tem-se buscado por fontes alternativas de energia, tais como a mistura gasosa conhecida como biogás. O biogás possui uma elevada concentração de metano, possibilitando o seu uso como combustível. Um dos seus componentes, o dióxido de carbono, possui efeito de redução de seu potencial energético, sendo vantajoso um processo de purificação para remoção desse composto. Para misturas com teor de metano superior a $96,5 \%$ de metano, entre outras, denomina-se o combustível de biometano e pode ser comercializado. Assim, o objetivo deste trabalho foi realizar o estudo da viabilidade econômica de um sistema proposto de coluna de absorção para purificação de biogás. Este foi realizado considerando um horizonte de 10 anos e Taxa Mínima de Atratividade (TMA) de 10\% a.a., utilizando o método da Taxa Interna de Retorno (TIR), por meio fluxo de caixa, que incluiu: uma estimativa do investimento; custos operacionais mensais estimados para um micro empreendimento individual e a vazão de biogás baseada na produção de propriedades do Oeste do Paraná. Por meio do fluxo de caixa determinou-se o preço mínimo de venda do biometano, para que o projeto fosse viável pelo método da TIR. A coluna de absorção projetada possui 5 pratos, 4,04m de altura e $17 \mathrm{~cm}$ de diâmetro. Os resultados obtidos indicaram que o sistema é viável economicamente, com preço mínimo de venda de $\mathrm{R} \$$ 0,93 por metro cúbico de biometano. O tempo de retorno do investimento foi de, aproximadamente, 6 anos.
\end{abstract}

PALAVRAS-CHAVE: Biometano. Remoção de $\mathrm{CO}_{2}$. Taxa interna de retorno.

\section{Página | 180}




\section{INTRODUÇÃO}

A escassez e aumento nos preços dos recursos energéticos tem levado a uma procura, a nível global, por fontes alternativas, tais como energia solar, eólica e de biomassa. Nesse contexto, uma tendência é a da recuperação energética de resíduos orgânicos, tais como resíduos industriais, resíduos sólidos municipais e resíduos agrícolas (MAGALHÃES et al., 2004; LESTINSKY et al., 2015).

Um dos processos utilizados para a conversão desses resíduos é o da digestão anaeróbia em biodigestores, que tem como produtos o biofertilizante, que pode ser aplicado na fertirrigação, e o biogás, que pode ser utilizado como fonte energética. Esse uso pode se dar na própria propriedade agrícola, como por exemplo, para geração de eletricidade, em motores de combustão interna ou como combustível veicular (GODOY JR., 2010; MARTINS et al., 2011; SUZUKI et. al, 2011).

Devido às características produtivas do país, percebe-se que há potencial para expansão da utilização dessa fonte energética. Estudo realizado por Souza

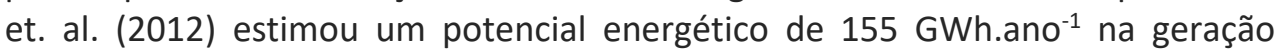
anual de resíduos de suinocultura apenas na região Oeste do Paraná, enquanto Sordi et. al. (2003) encontraram um potencial teórico de $142 \mathrm{MWh}^{2} \mathrm{ano}^{-1}$ para resíduos de avicultura na mesma região (MAGALHÃES et al., 2004).

Porém, para ampliar a sua utilização como fonte energética, processos de purificação se fazem necessários (YOUSEF et al., 2016), uma vez que o biogás é uma mistura gasosa contendo, principalmente, metano e dióxido de carbono, além de compostos em menor concentração, como vapor d'água e sulfeto de hidrogênio. Com exceção do metano, os demais compostos são indesejáveis, de modo que é necessário ampliar o conteúdo de metano do gás (SALIHU; ALAM, 2015). Uma concentração típica dos componentes do biogás pode ser observada na Tabela 1 (FNR, 2010).

Tabela 1 - Concentração típica dos componentes do biogás

$\begin{array}{cc}\text { Metano (CH4) } & \text { Concentração } \\ \text { Dióxido de carbono (CO2) } & 50-75 \% \text { mol.mol-1 } \\ \text { Água (H2O) } & 25-45 \% \text { mol.mol-1 } \\ \text { Sulfeto de hidrogênio (H2S) } & 2-7 \% \text {. mol.mol-1 (20-40 oC) } \\ \text { Nitrogênio (N2) } & 20-20.000 \text { ppm } \\ \text { Oxigênio (O2) } & <2 \% \text { mol.mol-1 } \\ \text { Hidrogênio (H2) } & <2 \% \text { mol.mol-1 } \\ \end{array}$

Fonte: FNR (2010).

Como pode ser observado na Tabela $1,0 \mathrm{CO}_{2}$ é um gás presente, geralmente, em elevadas concentrações. $\mathrm{O} \mathrm{CO}_{2}$ ocasiona um efeito de diluição no biogás, reduzindo seu potencial energético da ordem de $1 \mathrm{kWh} \cdot \mathrm{m}^{-3}$ a menos no poder calorífico do biogás para cada $10 \%$ de $\mathrm{CO}_{2}$ na mistura (MAGALHÃES, 2004). A redução de $\mathrm{CO}_{2}$ é interessante para melhorar a qualidade do biogás para aplicações na utilização como biocombustível veicular e injeção na rede de gás 
natural, que possuem especificações e padronização em suas características (MAGALHÃES et. al., 2004; AWE et al., 2017).

$\mathrm{O}$ processo de remoção do $\mathrm{CO}_{2}$ do biogás pode ser realizado por meio de diversas tecnologias, entre elas absorção, adsorção, separação por membranas e separação criogênica (NIE et al., 2013; LESTINSKY et al., 2015). O processo mais utilizado para o tratamento de biogás na Europa é a lavagem com água pressurizada em colunas de absorção, a qual se baseia na diferença entre as solubilidades, em água, do metano e do dióxido de carbono (FNR, 2010). Este processo envolve a transferência de massa em que um soluto gasoso presente em uma mistura de gases, é absorvido por um líquido no qual o soluto é mais ou menos solúvel (GEANKOPLIS,1993). O funcionamento básico desses equipamentos consiste na passagem de uma corrente gasosa (biogás) que flui em contracorrente com uma corrente líquida (água pressurizada), a qual absorverá o dióxido de carbono presente na corrente gasosa.

O acondicionamento dos fluidos em colunas ou torres, bem como a utilização de dispositivos como pratos dispostos ao longo da coluna, tem a função de ampliar a área de contato entre as duas correntes. As condições de operação podem sofrer grandes variações, dependendo da concentração de soluto nas duas correntes, da relação de equilíbrio do soluto para as ambas, e das condições de mistura para as correntes (BLACKADDER, 2004).

As vantagens do processo são: a sua flexibilidade, em que é possível ajustar a pressão, temperatura e capacidade do equipamento de acordo com o teor de $\mathrm{CO}_{2}$ do biogás bruto; a operação contínua e automática; fácil manutenção; a confiabilidade por ser um processo já comprovado na prática e o uso de um absorvente disponível, barato e seguro, que é a água. Algumas desvantagens são: a necessidade de pré-tratamento a montante; alto consumo de eletricidade e escape de metano absorvido na água, com taxa de aproximadamente $1 \%$, fator que exige combustão posterior (FNR, 2010). Porém, segundo Patterson et al. (2010), o metano dissolvido na água pode ser recuperado ao despressurizar a água a 2-4 bar em um tanque flash. De acordo com Haskoning (2000), a eficiência do processo é de, aproximadamente, $95 \%$.

Na prática, porém, a viabilidade técnica de um sistema, e mesmo a sua otimização, não garantem a sua aplicabilidade, uma vez que a implantação de um projeto demanda investimentos e recursos financeiros para manutenção. À medida em que as tecnologias de purificação e melhoramento do biogás evoluem rapidamente, são necessários estudos que as avaliem (AWE et al., 2017).

Dessa forma, uma avaliação de viabilidade econômica é necessária para verificar a possibilidade de implantação de um projeto. Para um estudo como esse, são requeridas informações acerca dos custos e benefícios econômicos do empreendimento, os quais podem ser utilizados para o cálculo de indicadores econômicos como tempo de retorno do investimento (payback) e Taxa Interna de Retorno (TIR).

Assim, o objetivo do trabalho consistiu na realização de um estudo de viabilidade econômica para um sistema proposto de purificação de biogás para remoção de dióxido de carbono por meio do processo de absorção pressurizada em coluna de pratos. 


\section{PROCEDIMENTOS METODOLÓGICOS}

\section{CARACTERIZAÇÃO DO SISTEMA ESTUDADO}

O sistema proposto contém uma coluna de absorção de pratos, através da qual ocorre a passagem de biogás pressurizado, em fluxo ascendente, e de água, em fluxo descendente, com o objetivo de remover a máxima quantidade de dióxido de carbono presente no biogás.

A definição da orientação dos fluxos foi feita com base nas recomendações de Blackadder (2004), segundo o qual o fluxo contracorrente é o mais utilizado, uma vez que isso garante que o gás próximo à saída da coluna entre em contato com o líquido alimentado, que não está saturado com o soluto e possui, portanto, maior capacidade de absorção. Nesse caso, opta-se geralmente pelo fluxo descendente para o líquido.

Na Figura 1 ilustra-se o fluxograma do processo, contendo os equipamentos e as condições operacionais.

Figura 1 - Fluxograma do sistema proposto para análise da viabilidade econômica

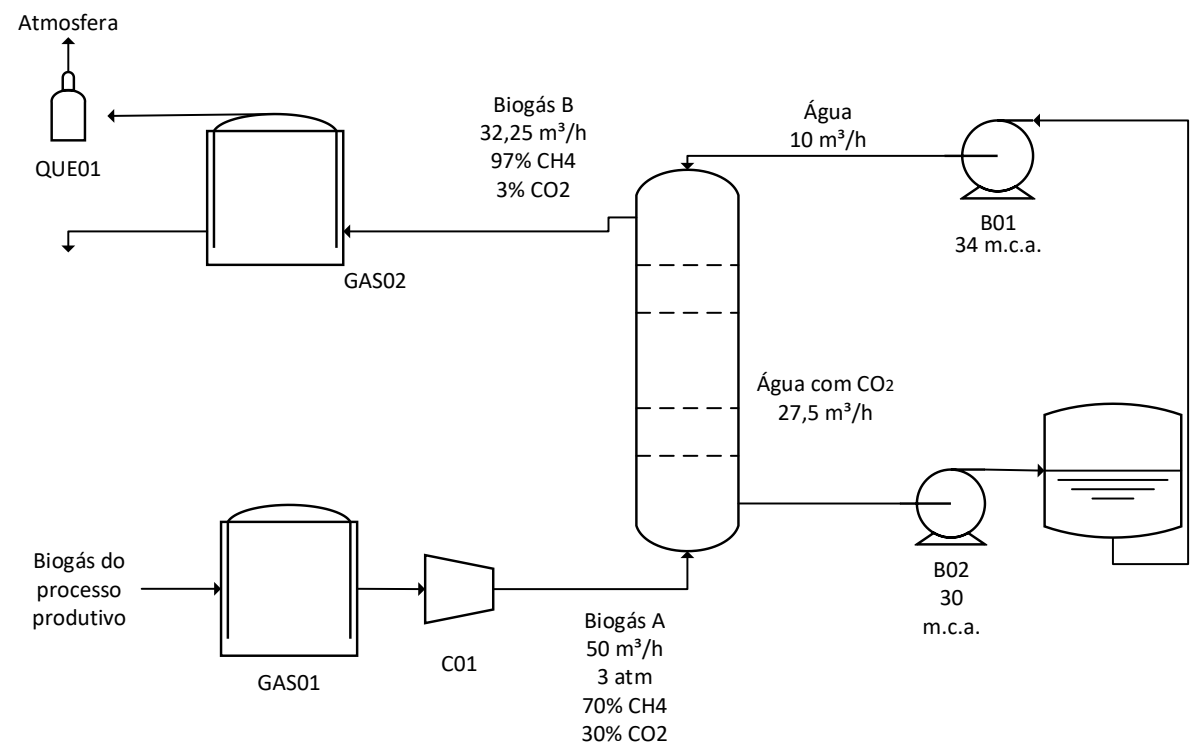

Fonte: Autoria própria (2018)

O funcionamento do processo apresentado na Figura 1 pode ser descrito da seguinte forma: o biogás a ser purificado é fornecido pelo reservatório de biogás (GAS01), passa pelo compressor (CO1) até alcançar uma pressão de trabalho de 3 atm. Esse biogás pressurizado é alimentado, a uma vazão de $50 \mathrm{~m}^{3} \cdot \mathrm{h}^{-1}$, na parte inferior da coluna de absorção (COLO1). A vazão de água, de $2783 \mathrm{~cm}^{3} . \mathrm{s}^{-1}$ (cerca de $10 \mathrm{~m}^{3} \cdot \mathrm{h}^{-1}$ ) é deslocada de um tanque T01 até a cota mais elevada com o auxílio de uma bomba B01, que vence um deslocamento positivo de cerca de 34 m.c.a. A água efluente, com vazão de cerca de $27,5 \mathrm{~m}^{3} \cdot \mathrm{h}^{-1}$ (sendo $17,5 \mathrm{~m}^{3} \cdot \mathrm{h}^{\text {- }}$ ${ }^{1}$ correspondentes ao $\mathrm{CO}_{2}$ ) é retornada ao tanque flash T01 para ser descomprimida e liberar $\mathrm{O} \mathrm{CO}_{2}$, enquanto o biometano $\left(33,2175 \mathrm{~m}^{3} \cdot \mathrm{h}^{-1}\right.$, correspondente à vazão de metano mais os $3 \%$ de $\mathrm{CO}_{2}$ ) é enviado a um gasômetro GAS02, sendo posteriormente encaminhado para venda. O gasômetro 
GAS02 possui um queimador (flare) QUE01 para emergências e queima de excesso.

\section{CARACTERIZAÇÃO DO SISTEMA ESTUDADO}

O dimensionamento da coluna foi realizado de acordo com as seguintes etapas: seleção das condições operacionais da coluna; estimativa da vazão de líquido necessária; cálculo do número de pratos teóricos; estimativa da altura da coluna; e cálculo do diâmetro da coluna.

A vazão de biogás utilizada, de $50 \mathrm{~m}^{3} \cdot \mathrm{h}^{-1}$, foi adotada a partir de valores da quantidade de biogás produzida em uma propriedade rural na região Oeste do Paraná. A pressão de trabalho de $3 \mathrm{~atm}$ foi selecionada de acordo com dados obtidos em artigos que tratam desse assunto (FNR, 2010; Xiao et al., 2014 e Magalhães et al., 2004).

A vazão de líquido necessária para as condições da coluna foi estimada utilizando a Equação 1 (MAGALHÃES et. al., 2004):

$$
\begin{aligned}
& V_{L} \\
& =\frac{V_{B}}{S \times P} \times \frac{N}{100}
\end{aligned}
$$

Na Equação (1), $V_{L}$ é a vazão de água necessária $\left(L \cdot \min ^{-1}\right) ; V_{B}$, a vazão de biogás $\left(\mathrm{cm}^{3} \cdot \mathrm{min}^{-1}\right)$; $\mathrm{S}$ é a solubilidade do $\mathrm{CO}_{2}$ em água $\left(\mathrm{cm}^{3} \cdot \mathrm{L}^{-1} \cdot \mathrm{atm}^{-1}\right) ; \mathrm{P}$ é a pressão de operação (atm), e $\mathrm{N}$ corresponde à concentração de $\mathrm{CO}_{2}$ no biogás (\%).

A solubilidade do $\mathrm{CO}_{2}$ em água, necessária para o cálculo do número de pratos teóricos da coluna, foi estimada através de dados de equilíbrio baseados na Lei de Henry (Equação 2):

$$
\begin{aligned}
& Y_{i} \cdot P \\
& =H \cdot X_{i}
\end{aligned}
$$

Em que $Y_{i}$ é a fração molar do soluto na fase gasosa, $X_{i}$, a fração molar do soluto na fase líquida, $P$ a pressão total do sistema, e $H$ a constante de Henry, a qual para o $\mathrm{CO}_{2}$ a $25^{\circ} \mathrm{C}$ equivale a $1.635 \mathrm{~atm}$ (PERRY, 2008). Apesar de o sistema ser pressurizado, foram utilizados valores para as constantes de Henry apenas em função da temperatura, uma vez que, segundo Buonicore (2000), não há variação significativa do valor de $H$ em função da pressão.

Nos cálculos de projeto, utilizaram-se os valores absolutos para as vazões e para as frações molares do componente, onde a vazão absoluta consiste na vazão de gás ou líquido inerte (sem o soluto), e as frações absolutas consistem na razão entre a vazão molar de soluto, e a vazão molar de líquido ou gás inertes.

Para o estudo, considerou-se um biogás com a composição apresentada na Tabela 2. 
Tabela 2 - Composição do biogás considerado para o estudo

\begin{tabular}{cc} 
Componente & Concentração (mol.mol-1) \\
Metano (CH4) & $64,5 \%$ \\
Dióxido de carbono (CO2) & $35 \%$ \\
Sulfeto de hidrogênio (H2S) & $0,5 \%$ \\
\hline
\end{tabular}

Fonte: Autoria própria (2018)

Para a realização dos balanços molares, considerou-se o biogás como uma mistura binária de gás carbônico e outros gases classificados como "não-gás carbônico", sendo o metano em sua maioria, bem como uma pequena fração de sulfeto de hidrogênio. A massa específica molar média de uma mistura binária (componentes A e B) é obtida pela expressão demonstrada na Equação (3):

$$
\begin{aligned}
& \rho_{\text {média }} \\
= & \rho_{A} X_{A} \\
+ & \rho_{B}(1 \\
- & \left.X_{A}\right)
\end{aligned}
$$

Em que $\rho_{A}$ e $\rho_{B}$ correspondem à densidade do componentes $\mathrm{A}$ e $\mathrm{B}$, respectivamente, e $X_{A}$ corresponde à fração molar do componente $A$ na mistura.

A partir do valor encontrado pela Equação (3), realizaram-se as simulações dos balanços de massa para cada prato da coluna, com diversos valores de vazão a fim de encontrar um valor que se aproximasse do valor desejado da concentração de $\mathrm{CO}_{2}$ na saída do biogás tratado. Este valor foi determinado de acordo com as especificações para obter-se biometano. De acordo com a Resolução $\mathrm{n}^{\circ} 08$ de 30 de janeiro de 2015 da Agência Nacional do Petróleo, a concentração máxima $\mathrm{CO}_{2}$ para que o biogás seja considerado biometano é de $3 \%$.

Assim, o cálculo do número de pratos teóricos foi realizado por meio da equação de equilíbrio e de balanços de massa por componente para cada prato da coluna. À medida que os cálculos para cada prato são realizados, utilizando os valores obtidos nos anteriores, a fração molar do componente $\mathrm{CO}_{2}$ no gás diminui, até atingir-se o valor desejado de $3 \%$. Uma ilustração do fluxo de biogás e de líquido em cada um dos pratos encontra-se representado na Figura 2.

Figura 2 - llustração dos fluxos gasoso e líquido em pratos consecutivos no interior da coluna

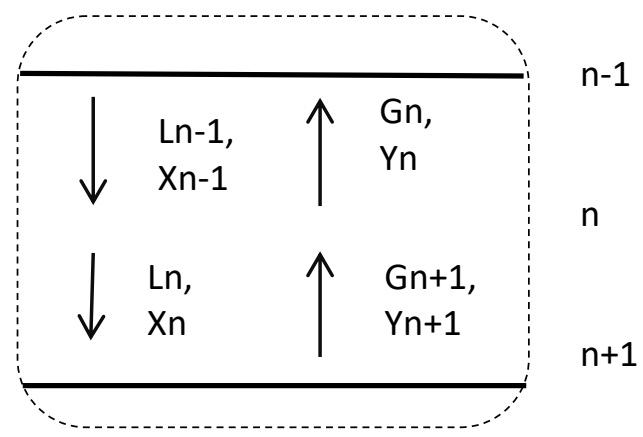

Fonte: Autoria própria (2018) 
Partindo do prato $n$, tem-se os valores das vazões livres de soluto de gás $(G)$ e líquido (L), e a fração molar absoluta do $\mathrm{CO}_{2}$ no biogás $\left(\mathrm{Y}_{\mathrm{n}+1}\right)$ que entra no prato. Foi possível calcular a fração molar absoluta do $\mathrm{CO}_{2}$ no solvente que deixa o prato $(\mathrm{Xn})$, sabendo-se a massa de $\mathrm{CO}_{2}$ que deve ser absorvida na coluna. Com o valor de Xn, utilizando-se a Equação (2), foi possível calcular a fração molar absoluta do componente no gás que deixa o prato $(\mathrm{Yn})$. Dispondo desses valores, calculou-se a fração molar absoluta do componente no líquido que entra no prato $(\mathrm{Xn}-1)$, através do seguinte balanço de massa (Equação 4):

$$
\begin{aligned}
& L\left(X_{n-1}\right) \\
+ & G\left(Y_{n+1}\right) \\
= & L\left(X_{n}\right) \\
+ & G\left(Y_{n}\right)
\end{aligned}
$$

O cálculo foi repetido para cada prato, até chegar-se a um valor de Yn menor ou igual a $3 \%$.

A altura da coluna foi determinada pelo espaçamento dos pratos, seguindo as recomendações propostas por Spellman e Whiting (2004), de que o espaçamento usual varia de 45 a $70 \mathrm{~cm}$, tendo sido adotado o valor de $61 \mathrm{~cm}$.

O diâmetro mínimo da coluna foi calculado de acordo com a equação (5) (SPELLMAN; WHITING, 2004):

$$
\begin{gathered}
d= \\
\psi\left[Q\left(\rho_{g}\right)^{0,5}\right]^{0,5}
\end{gathered}
$$

Na Equação (5), $d$ é o diâmetro da torre $(m), Q$ é a vazão volumétrica de gás $\left(\mathrm{m}^{3} / \mathrm{h}\right), \rho_{g}$ é a densidade do biogás $\left(\mathrm{kg} \cdot \mathrm{m}^{-3}\right)$, a ser estimada por meio de média ponderada dos componentes, e $\psi$ é uma correlação empírica $\left(\mathrm{m}^{0,25} \cdot \mathrm{h}^{0,25} \cdot \mathrm{kg}^{0,25}\right)$, cujo valor para uma coluna de pratos "sieve tray" cujo espaçamento entre os pratos é de $61 \mathrm{~cm}$, é igual a 0,014 (SPELLMAN e WHITING, 2004 , p. 179). Conhecendo um valor para o diâmetro mínimo, adotou-se um valor um pouco maior para o diâmetro da coluna, por critério de segurança.

\section{ESTUDO DE VIABILIDADE ECONÔMICA}

A análise de viabilidade econômica da coluna de absorção foi realizada levando em consideração, de um lado, os custos do projeto (investimento e custos de operação) e, de outro, a receita obtida com a venda do biometano.

Considerou-se um cenário em que o biogás fosse adquirido de um produtor rural, enquanto que a análise de viabilidade permitiu determinar o preço de venda mínimo para que o projeto fosse viável economicamente, de acordo com a ferramenta da Taxa Interna de Retorno. Posteriormente, o valor de venda encontrado foi comparado com valores usuais e de instruções normativas para concessão de Gás Natural, de modo a verificar se condiz com a realidade de mercado.

O método da Taxa Interna de Retorno pressupõe uma comparação entre a TIR e a TMA, de acordo com os seguintes critérios (HIRSCHFELD, 2010):

a) Se TIR = TMA, a alternativa é aceitável como um investimento financeiro, em que a taxa de retorno é igual à taxa mínima de atratividade, ou seja, 
será aceitável se apresentar riscos semelhantes ou inferiores ao do investimento utilizado para comparação cuja taxa é a Taxa Mínima de Atratividade;

b) Se TIR > TMA, o investimento é bem aceitável, ou seja, a alternativa é viável;

c) Se TIR < TMA, o investimento não é bem aceitável, ou seja, não é viável.

Assim, a metodologia do estudo de viabilidade econômica deu-se de acordo com as seguintes etapas, que serão descritas posteriormente:

a) Escolha da Taxa mínima de atratividade (TMA) adotada para comparação;

b) Estimativa dos custos do investimento;

c) Cálculo da receita necessária para que TIR se iguale a TMA;

d) Cálculo do preço de venda necessário para se obter a receita calculada;

e) Cálculo do Valor Presente Líquido (VPL) do investimento;

f) Comparação do preço de venda mínimo com valores usuais do mercado.

Neste estudo foram assumidas as seguintes hipóteses: A TMA foi adotada de acordo com valores usuais, conforme o grau de segurança desejado para o investimento, tendo sido escolhido o valor de $10 \%$ a.a. por ser um valor considerado conservador; a estimativa do investimento foi realizada selecionando-se equipamentos que atenderiam a necessidade do projeto, bem como dos materiais para construção da coluna, após definição de suas dimensões, e buscando-se dados para seu preço de compra com fornecedores ou na literatura; os custos operacionais mensais foram estimados a partir de valores usuais no mercado; o sistema proposto foi caracterizado como microempreendimento individual, ficando isento dos tributos nacionais federais, tais como Imposto de Renda, PIS, Cofins, IPI e CSLL.

Os custos operacionais incluíram os seguintes itens:

- Mão-de-obra: salário mensal do operador do sistema (para o qual considerou-se valor um pouco superior ao de um salário mínimo), mais os encargos trabalhistas, como FGTS, INSS, férias, $13^{\circ}$ salário, os quais, para microempresas, correspondem a $32 \%$ do salário do funcionário;

- Pro-labore do empreendedor, para o qual considerou-se o valor de um salário mínimo, mais os valores correspondente à Previdência Social, o que, de acordo com a classificação do empreendimento, equivale a $\mathrm{R} \$ 37,20$ mensais;

- Custos de manutenção do sistema, estimados com base nos valores de plantas similares;

- Depreciação dos bens, a partir das taxas especificadas na Instrução normativa SRF n 162, de 31 de dezembro de 1998, exceto para as bombas e compressores, para os quais estimou-se a depreciação com base no tempo de vida, o qual é inferior ao usual devido à corrosão provocada pelo gás sulfídrico;

- Custo de aquisição do biogás, cujo valor por metro cúbico $(R \$ 0,157)$ foi adotado conforme o encontrado em estudo realizado por Bohn et. al. (2014). 
- Custos com energia elétrica, para a qual considerou-se a Tarifa Convencional Rural da Companhia Paranaense de Energia Elétrica (COPEL), com valor de R\$ 0,4518 / kWh.

O custo total de aquisição do biogás foi calculado considerando uma vazão de biogás de $50 \mathrm{~m}^{3} \cdot \mathrm{h}^{-1}$, equivalente à produção de uma propriedade rural na região Oeste do Paraná, e o funcionamento de 8 h por dia, 22 dias por mês.

Os custos mensais com energia elétrica foram calculados considerando o mesmo tempo de funcionamento para cada um dos equipamentos. Os valores de potência encontram-se na Tabela 3.

Tabela 3 - Potência dos equipamentos

\begin{tabular}{ccc} 
Equipamento & Potência (kWh) & Custo/h (R\$̣) \\
Bomba B01 & 2,2 & 0,99 \\
Bomba B02 & 2,2 & 0,99 \\
Compressor C01 & 5,4 & 2,44 \\
\hline
\end{tabular}

Fonte: Dados obtidos de

http://www.agrolinkholambra.com.br/pdf/bombas/schneider.pdf e http://www.lojadomecanico.com.br/produto/64520/11/159/compressor-de-ar-onix--30pes-250-litros-175-libras-trifasico

A TIR foi calculada utilizando o software Microsoft Excel ${ }^{\circ}$ v. 2013, por meio de uma planilha de células com o fluxo de caixa do projeto, considerando um horizonte de 10 anos para o empreendimento, que corresponde ao tempo de vida útil da coluna de absorção. Considerou-se o valor do investimento como despesa em um instante zero, e para cada ano atribuiu-se um valor fixo de custos operacionais e de receita. $\mathrm{O}$ cálculo da receita do projeto foi realizado a partir de uma situação em que o biometano produzido no processo fosse vendido como combustível. Valores para o preço de venda foram inseridos na planilha e ajustados progressivamente, até se encontrar o valor mínimo no qual a TIR se iguale à TMA.

Esse valor mínimo foi comparado com valores usuais do mercado por $\mathrm{m}^{3}$ de Gás Natural e biometano para concessão a companhias autorizadas para distribuição de Gás Natural no país, de acordo com a Resolução ANP n 52/2011. As referências utilizadas para comparação foram os valores de concessão adotados pela Companhia de Gás de São Paulo (COMGÁS), segmento de Gás Natural Veicular, dispostos na Deliberação ARSESP n 716 de 2017, bem como o valor máximo para concessão de biometano, modalidade injeção na rede, adotado pela Companhia de Gás do Estado do Rio Grande do Sul (SULGÁs), no Edital $n^{\circ} 01 / 15$.

O VPL também foi calculado utilizando o fluxo de caixa elaborado na ferramenta Microsoft Excel ${ }^{\circ}$ v. 2013. A teoria indica que o cálculo do VPL requer o conhecimento do valor total de desembolso com o projeto, no instante inicial, e das projeções dos valores anuais obtidos da geração de caixa durante o período de $n$ anos, os quais devem ser convertidos nos valores atuais. Após, são realizadas as seguintes etapas (SCHUBERT, 1989):

a) Cálculo do valor presente do fluxo de caixa líquido do investimento;

b) Cálculo do valor presente dos desembolsos de caixa do projeto; 
c) Apuração do valor presente líquido.

A Equação 6 descreve o VPL (HIRSCHFELD, 2010):

$$
\begin{array}{r}
V P L_{j}= \\
\sum_{0}^{n} F_{n}(1+ \\
i)^{-n}
\end{array}
$$

Em que $\mathrm{VPL}_{\mathrm{j}}$ corresponde ao Valor Presente Líquido do fluxo de caixa da alternativa $\mathrm{j} ; \mathrm{n}$ ao número de períodos envolvidos em cada elemento do fluxo de caixa; $F_{n}$ a cada um dos valores envolvidos no fluxo de caixa que ocorrem em $n$ períodos; e i à Taxa Mínima de Atratividade.

Segundo Schubert (1989), o método para encontrar a TIR, consiste em igualar o valor presente dos desembolsos de caixa aplicados no projeto ao valor presente do fluxo de caixa líquido esperado do projeto.

A taxa de desconto $\mathrm{k}_{0}$ iguala o valor atual dos ingressos de recursos ao valor do desembolso total do empreendimento. Desse modo, o projeto será aceito se a taxa $\mathrm{k}_{0}$ for igual ou maior que o custo de capital. Esquematicamente, tem-se na Equação (7) (SCHUBERT, 1989):

$$
\sum_{t=0}^{n} \frac{I_{a}=}{\left(1+k_{0}\right)^{t}}
$$

Onde $n$ é o número de períodos considerados, $k_{0}$ é a taxa de desconto, $F C L$ é o fluxo de caixa líquido, e $t$ é o tempo.

\section{RESULTADOS E DISCUSSÃO}

\section{DIMENSIONAMENTO DA COLUNA DE ABSORÇÃO}

A partir dos dados adotados para a coluna, do balanço de massa global para a coluna e de balanços de massa por componente para cada prato, foi possível calcular o número de pratos (ou estágios) teóricos necessários para atingir a concentração de $\mathrm{CO}_{2}$ desejada na corrente gasosa que deixa a coluna. Na Tabela 4 são apresentadas as frações molares do componente nas correntes líquida e gasosa que deixam cada prato.

Tabela 4 - Frações molares de $\mathrm{CO}_{2}$ nas correntes líquida e gasosa para cada prato

\begin{tabular}{ccc} 
Prato & $\begin{array}{c}\text { Fração molar de } \mathrm{CO}_{2} \text { no } \\
\text { líquido }\end{array}$ & $\begin{array}{c}\text { Fração molar de } \\
\mathrm{CO}_{2} \text { no gás }\end{array}$ \\
\hline 1 (topo) & $5,6263 \mathrm{E}-05$ & 0,02975 \\
2 & $1,3706 \mathrm{E}-04$ & 0,06951 \\
3 & $2,5238 \mathrm{E}-04$ & 0,12094 \\
4 & $4,1698 \mathrm{E}-04$ & 0,18523 \\
5 (fundo) & $6,5187 \mathrm{E}-04$ & 0,26226 \\
\hline
\end{tabular}

Fonte: Autoria própria (2018) 
Como é possível observar na Tabela 4, o total de 5 pratos foi necessário para que se atingisse, na vazão de biogás que deixa o prato do topo, uma fração molar de $\mathrm{CO}_{2}$ inferior a $3 \%$.

\section{DIMENSÕES DA COLUNA}

A partir do número de estágios teóricos necessários (5 pratos), e do espaçamento adotado entre dois pratos consecutivos $(61 \mathrm{~cm})$, foi possível encontrar a altura da coluna. Considerando um espaçamento de $80 \mathrm{~cm}$ entre a base da coluna e o primeiro prato, e entre o último prato e o topo da coluna, o valor encontrado foi de 4,04 m. O diâmetro mínimo para a torre, calculado pela Equação (5), foi igual a $4 \mathrm{~cm}$, de modo que adotou-se um valor superior. $O$ valor adotado foi de $17 \mathrm{~cm}$ de diâmetro. Dessa forma, a coluna de absorção apresenta as dimensões que podem ser visualizadas na Tabela 5 .

Tabela 5 - Dimensões da coluna de absorção

\begin{tabular}{cc} 
Parâmetro & Dimensão \\
Altura & $4,04 \mathrm{~m}$ \\
Diâmetro & $17 \mathrm{~cm}$ \\
Volume & $0,09 \mathrm{~m}^{3}$ \\
Área do prato & $210 \mathrm{~cm}^{2}$ \\
\hline
\end{tabular}

Fonte: Autoria própria (2018)

\section{ESTUDO DE VIABILIDADE ECONÔMICA}

O levantamento realizado com fornecedores de equipamentos nacionais permitiu estimar os custos do investimento e os custos operacionais do projeto. Na Tabela 6 são apresentados os custos do investimento.

Tabela 6 - Custos estimados para o investimento do projeto

$\begin{array}{cc}\text { Item } & \text { Custo (R\$) } \\ \text { Coluna } & 4.670,00 \\ \text { Bombas } & 2.000,00 \\ \text { Compressor } & 4.540,00 \\ \text { Queimador (Flare) } & 500,00 \\ \text { Instalação física (estrutura e tubulações) } & 3.225,50 \\ \text { Tanque } & 5.890,00 \\ \text { Gasômetros } & 10.000,00 \\ \text { Implantação (mão-de-obra) } & 4.737,20 \\ \text { Total } & \mathbf{3 5 . 5 6 2 , 7}\end{array}$

Fonte: Autoria própria (2018)

Os custos operacionais mensais estão apresentados na Tabela 7. 
Tabela 7 - Estimativa de custos operacionais mensais

$\begin{array}{cc}\text { Item } & \text { Custo (R\$) } \\ \text { Mão-de-obra } & 937,00 \\ \text { Encargos trabalhistas } & 299,84 \\ \text { Pró-labore } & 937,00 \\ \text { Previdência social } & 37,20 \\ \text { Manutenção } & 300,00 \\ \text { Depreciação } & 332,58 \\ \text { Aquisição do biogás para purificação } & 1.381,60 \\ \text { Energia elétrica } & \mathbf{7 8 8 , 8 3} \\ \text { Total } & \mathbf{4 9 5 7 , 3 7}\end{array}$

Fonte: Autoria própria (2018)

O valor de venda mínimo encontrado para que a TIR do investimento se iguale à TMA adotada foi de $\mathrm{R} \$ \mathbf{0 , 9 3}$ por metro cúbico de biometano. No Edital $\mathrm{n}^{\circ}$ 01/2015, a Sulgás-RS determinou um preço máximo de $R \$ \$ 0,99 / \mathrm{m}^{3}$ para concessão na modalidade injeção na rede, ao passo que, na Deliberação ARSESP $n^{\circ} 716 / 2017$, as tarifas determinadas para concessão pela COMGÁS-SP, na modalidade GNV, são de $\mathrm{R} \$ 1,194971 / \mathrm{m}^{3}$ para postos de combustíveis, R\$ $1,107135 / \mathrm{m}^{3}$ para transporte público, e $\mathrm{R} \$ 1,107135 / \mathrm{m}^{3}$ para frotas. Assim, ao comparar o preço mínimo de venda para viabilidade do investimento com os valores usados como referência, verifica-se que o preço de venda está razoável e dentro das possibilidades do mercado, comprovando assim, a viabilidade do projeto proposto.

O gráfico do fluxo de caixa anual para os 10 anos de horizonte de projeto, está apresentado na Figura 3.

Figura 3 - Fluxo de caixa acumulado anual do projeto

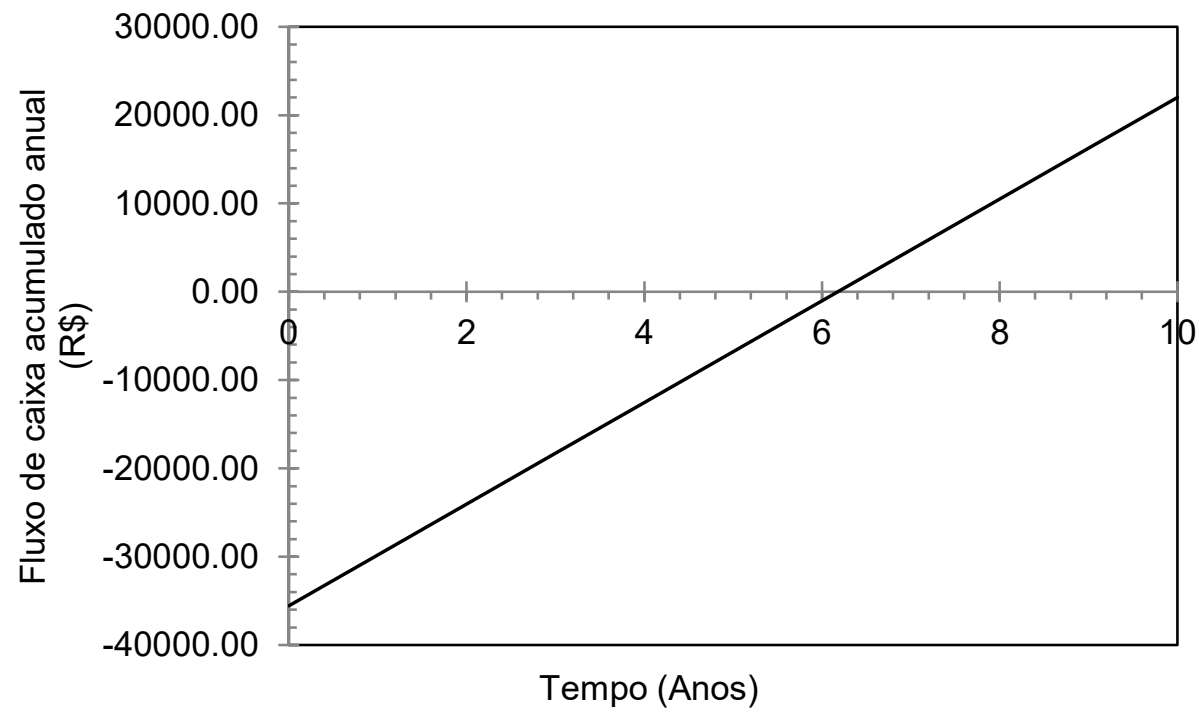

Fonte: Autoria própria (2018) 
Os indicadores utilizados para verificar a viabilidade econômica do projeto (Payback, VPL e TIR) estão apresentadas na Tabela 8, bem como a TMA utilizada para comparação.

Tabela 7 - Estimativa de custos operacionais mensais

$\begin{array}{cc}\text { Indicador } & \text { Valor } \\ \begin{array}{c}\text { Tempo de retorno do investimento } \\ \text { (Payback) }\end{array} & 6,17 \text { anos } \\ \text { Valor Presente Líquido } & \mathrm{R} \$ 3060,84 \\ \text { Taxa Interna de Retorno } & 10 \% \\ \text { Taxa Mínima de Atratividade } & 10 \%\end{array}$

Fonte: Autoria própria (2018)

Os valores dos indicadores demonstram a viabilidade econômica do sistema, uma vez que o tempo de retorno é inferior ao horizonte de projeto, o VPL é positivo e, principalmente, mesmo tendo sido adotado um valor conservador para TMA, o preço de venda mínimo é razoável no mercado atual, sendo inferior a valores de concessão utilizados para comparação. Isso significa que, nas condições apresentadas, o projeto é vantajoso do ponto de vista econômico, sendo possível estabelecer um preço de venda levemente mais alto, de modo que os benefícios econômicos obtidos com sua implantação suplantem o risco do investimento. Portanto, a purificação de biogás, até atingir a composição de um biocombustível, mostra-se viável e pode ser uma solução para a perda de atratividade após a resolução de compensação elétrica publicada pela Aneel (Resolução n 482/2012).

\section{CONCLUSÕES}

Os valores encontrados para as dimensões da coluna de absorção proposta corresponderam a 5 pratos, altura de $4,04 \mathrm{~m}$ e diâmetro de $17 \mathrm{~cm}$, sendo valores praticáveis e comprovando assim a viabilidade técnica do sistema. O dimensionamento foi realizado considerando condições de vazão de entrada de biogás de $50 \mathrm{~m}^{3} \cdot \mathrm{h}^{-1}$, e concentração inicial de $\mathrm{CO}_{2}$ no biogás de $35 \%$.

A viabilidade econômica do sistema também foi comprovada, após análise de indicadores econômicos, especificamente a Taxa Interna de Retorno, por meio da qual se encontrou um preço mínimo de venda de $\mathrm{R} \$ 0,93$ por metro cúbico que se mostrou razoável dentro das perspectivas do mercado. Para o sistema proposto, o custo operacional mensal correspondeu a $14 \%$ do valor do investimento. 


\title{
Scaling and economic feasibility evaluation of an absorption column applied to biogas upgrading
}

\begin{abstract}
In the last few decades, there has been an effort in searching for alternative energy sources, such as biogas, a gas mixture that presents a high methane concentration, allowing its use as fuel. One of its components, carbon dioxide, causes an effect of reducing its energetic potential, so that a upgrading process to remove it from biogas is advantageous. For mixtures in which the methane content is superior to $96.5 \%$, the fuel is therefore known as biomethane and may be commercialized. Therefore, the purpose of this paper was to carry out an economical feasibility evaluation study of an absorption column proposed system for biogas purification. The economical evaluation was carried out considering a project 10 years long and a Minimal Atractiveness Rate (MAR) of 10\% per year, through the Internal Rate of Return (IRR) method, by means of an spreadsheet for the cash flow. The cash flow included an investiment estimate; operational monthly costs estimated for an individual microentrepreneur, and a biogas workflow based on the production of rural properties in the west region of Parana state. Through the cash flow it was determined the minimal biomethane cubic meter sale price for the project to be economically feasible according to the IRR method. The absorption column projected has 5 trays, $4,04 \mathrm{~m}$ of height and diameter of $17 \mathrm{~cm}$. The system proved to be economically feasible, with a minimum biomethane sale price of $R \$ 0,93$ per biomethane cubic meter. The payback time for the investment is of approximately six years.
\end{abstract}

KEYWORDS: Biomethane. $\mathrm{Co}_{2}$ removal. Internal return rate. 
REFERÊNCIAS

AGÊNCIA BRASILEIRA DE ENERGIA ELÉTRICA (ANEEL). Resolução Normativa $\mathbf{n}^{\circ}$ $482 / 2012$

AGÊNCIA BRASILEIRA DE ENERGIA ELÉTRICA (ANEEL). Resolução Homologatória $\mathbf{n}^{\circ}$ 2.096, 21 de junho de 2016.

AGÊNCIA NACIONAL DE PETRÓLEO (ANP). Resolução $n^{\circ}$ 52, de 29 de setembro de 2011.

AGÊNCIA NACIONAL DE PETRÓLEO (ANP). Resolução $n^{\circ} 08$ de $\mathbf{3 0}$ de janeiro de 2015.

AGÊNCIA REGULADORA DE SANEAMENTO E ENERGIA DO ESTADO DE SÃO PAULO (ARSESP). Deliberação $n^{\circ} \mathbf{7 1 6}$ de $\mathbf{3 0}$ de março de 2017.

AWE, O.; ZHAO, Y.; NZIHOU, A.; MINH, D. P.; LYCZKO, N. A review of biogas utilization, purification and upgrading technologies. Waste and Biomass valorization, v. 8 (2), p. 267-283, 2017.

BLACKADDER, D. A.; NEDDERMAN, R. Manual de operações unitárias: destilação de sistemas binários, extração de solvente, absorção de gases, sistemas de múltiplos componentes, trocadores de calor, secagem, evaporadores, filtragem. São Paulo: Hemus, 1982. xi, 276 p

BOHN, C.; MAIA, D.; NIKLEVICZ, R. R.; PEREIRA, N. C.; GIMENES, M. L.; FRARE, L. M. Impacto econômico da purificação de biogás no processo de geração de energia elétrica em um frigorífico de aves. $\mathbf{X X}$ Congresso Brasileiro de Engenharia Química. Florianópolis, 2014.

BUONICORE, Davis Wayne. Manual de engenharia de poluição atmosférica. 2. Ed. Nova lorque: Wiley, 2000.

CASAROTTO FILHO, Nelson; KOPITTKE, Bruno Hartmut. Análise de investimentos: matemática financeira, engenharia econômica, tomada de decisão, estratégia empresarial. 11. ed. São Paulo: Atlas, 2010. xiv, 411 p.

COMPANHIA DE GÁS DO RIO GRANDE DO SUL (SULGÁS). Edital de chamada pública $n^{\circ}$ 01/2015 - Seleção de propostas para aquisição de biometano. 2015. Disponível em: < http://www.sulgas.rs.gov.br/sulgas/images/pdf/2015/CP_01_15/C_Publica_01_1 5_Edital.pdf>. Acesso em: 17 de maio de 2017. 
DREW, J. W.; GINDER, A. F. How to estimate the cost of pilot-plant equipment. Chemical Engineering, February 9, 1970.

FACHAGENTUR NACHWACHSENDE ROHSTOFFE E.V. (FNR). Guia prático do Biogás. 5a edição, totalmente revista e atualizada, Gülzow, 2010.

GEANKOPLIS, Christie J. Transport Processes and Unit Operations. 3rd ed. New Jersey: Prentice Hall, 1993. 921 p.

GODOY JUNIOR, Ederaldo. Desenvolvimento e avaliação de uma miniestação ecoeficiente de tratamento de esgoto e reuso de águas, com sistemas registrador queimador, para baixas vazões de biogás e cogeração de energia. Universidade Estadual Paulista "Júlio De Mesquita Filho" Faculdade De Engenharia (Campus De Guaratinguetá) 2010. Tese de doutorado.

GREEN, Don W. Perry's Chemical Engineer's Handbook. $8^{\text {a }}$ ed. New York: McGraw-Hill, 2008.

HASKONING Consulting Engineers and Architects. Technical summary on gas treatment. Netherlands, 2000.

HIRSCHFELD, Henrique.Engenharia econômica e análise de custos: aplicações práticas para economistas, engenheiros, analistas de investimentos e administradores. 7. ed. rev. atual. ampl. São Paulo: Atlas, 2009. 519 p.

LASTELLA, G. et al. Anaerobic digestion of semi-solid organic waste: biogas production its purification. Pergamon Energy Conservasion e management. 2002.

LESTINSKY, P.; VECER, M.; NAVRATIL, P.; STEHLIK, P. The removal of $\mathrm{CO}_{2}$ from biogas using a laboratory PSA unit: Design using breakthrough curves. Clean Technologies nd Environmental Policy, v. 17(5), p. 1281-1289, 2015.

MAGALHÃES, E. A.; SOUZA, S. N. M; AFONSO, A. D. L.; RICIERI, R. P.. Confecção e avaliação de um sistema de remoção de $\mathrm{CO}_{2}$ no biogás. Acta Scientiarum. Technology. Maringá, v. 26, no. 1, p. 11-19, 2004.

MARTINS, F. M.; OLIVEIRA, P. A. V. Análise econômica da geração de energia elétrica a partir do biogás na suinocultura. Engenharia Agrícola, v.31(3), p.477486,2011 . crossref 
NIE, Hong; JIANG, Hao; CHONG, Daowen; WU, Quangui; XU, Chunming; ZHOU, Hongjun. Comparison of water scrubbing and propylene carbonate adsorption for biogás upgrading process. Energy Fuels, 27(6), p. 3239-3245, 2013. crossref

PATTERSON, Tim; ESTEVES, Sandra; DINSDALE, Richard, GUWY, Alan. An evaluation of the policy and techno-economic factors affecting the potential for biogas upgrading for transport fuel use in the UK. Energy Policy, v. 39(3), p. 1806-1816, 2011. crossref

PERLINGEIRO, Carlos Augusto G.. Engenharia de Processos: Análise, simulação, otimização e síntese de processos químicos. São Paulo: Bluncher, 2005.

PORTAL ACERVO LEIS. Depreciação. Disponível em: < http://www.acervoleis.com.br/popuplei.asp?lei_id=66876>. Acesso em: 20 novembro 2014.

RECEITA FEDERAL. Instrução normativa SRF n 162, de 31 de dezembro de 1998.

SALIHU, A.; ALAM, Z. Upgrading strategies for effective utilization of biogas. Environmental progress \& Sustainable Energy, v. 34 (5), p. 1512-1520, 2015. crossref

SCHUBERT, Pedro. Análise de Investimentos e taxa de retorno. São Paulo: Ática S.A., 1989.

SEBRAE, s.d. Microempreendedor individual. Disponível em: < http://www.portaldoempreendedor.gov.br/mei-microempreendedorindividual>. Acesso em: 20 novembro 2014.

SORDI, A. et al. Potencial energético dos resíduos de aviário de frangos de corte na região Oeste do Paraná. In: CONGRESSO BRASILEIRO DE ENGENHARIA AGRíCOLA - CONBEA, 32. 2003. Goiânia - GO. Anais.... Goiânia - GO, CONBEA/SBEA. 2003.1 CDROM.

SOUZA, J.; BORBA, A. P.; CARDOSO, M. L.; COELHO, A. A.; SCHAEFFER, L. Planta para compressão e tratamento do biometano. In: Congresso Internacional de Tecnologias para o Meio Ambiente, 3, 2012, Bento Gonçalves. Anais eletrônicos... Bento Gonçalves: PROAMB, 2012.

SPELLMAN, Frank R; WHITING, Nancy E. Environmental Engineer's Mathematics Handbook. CRC Press LCC, 2004. 
SUZUKI, A B. P.; FERNANDES, D. M.; FARIA, R. A. P.; VIDAL, T. C. M. Uso de biogás em motores de combustão interna. Pesquisa Aplicada \& Agrotecnologia, v. 4(1), p. 221-237, 2011.

ULRICH, Gael D. A Guide to Chemical Engineering Process Design and Economics. New York: John Wiley e Sons, 1984.

YOUSEF, A.; ELDRAINY, Y.; EL-MAGHLANY, W.; ATTIA, A. Upgrading biogas by a low-temperature $\mathrm{CO}_{2}$ removal technique. Alexandria Engineering Journal, $v$. 55(2), p. 1143-1150, 2016. crossref

Recebido: 02 junho 2017

Aprovado: 15 março 2018

DOI: 10.3895/gi.v14n1.5964

Como citar:

GASPAROVIC, C. L. M.; EYNG, E.; FRARE, L. M.; SABBI, L. B. C. Dimensionamento e avaliação da viabilidade técnica e econômica de uma coluna de absorção para purificação de biogás. R. Gest. Industr., Ponta Grossa, v. 14, n. 1, p. 180-197, jan./mar. 2018. Disponível em: <https://periodicos.utfpr.edu.br/rgi>. Acesso em: XXX.

Correspondência:

Claudia Luiza Manfredi Gasparovic

Universidade Tecnológica Federal do Paraná, Av. Brasil, 4232, Medianeira, Paraná, Brasil.

Direito autoral: Este artigo está licenciado sob os termos da Licença Creative Commons-Atribuição 4.0 Internacional.

\section{(c) (1)}

